CLINICAL STUDY

\title{
Metabolic abnormalities in patients with normocalcemic hyperparathyroidism detected at a population-based screening
}

\author{
Emil Hagström ${ }^{1}$, Ewa Lundgren ${ }^{1}$, Jonas Rastad ${ }^{1,2}$ and Per Hellman ${ }^{1}$ \\ ${ }^{1}$ Endocrine Unit, Department of Surgical Sciences, Uppsala University, University Hospital, SE-751 85 Uppsala, Sweden and ${ }^{2}$ Clinical Science, \\ AstraZeneca R\&D, Södertälje, Sweden
}

(Correspondence should be addressed to E Hagström; Email: emil.hagstrom@surgsci.uu.se)

\begin{abstract}
Objective: Dyslipidemia, hypertension, diabetes mellitus and also primary hyperparathyroidism (pHPT) are associated with an increased risk of cardiovascular diseases. Metabolic abnormalities in mild pHPT have been reported, but never in cases with normal calcium and high parathyroid hormone (PTH) levels, i.e. suffering from 'normocalcemic pHPT'. Our aim was to explore the occurrence of these metabolic abnormalities in individuals with normocalcemic pHPT identified in a population-based screening, and the effects of parathyroidectomy vs conservative treatment on metabolic variables. Design and methods: A population-based screening of 5202 post-menopausal women identified 30 patients with normal calcium, inappropriately high PTH and normal creatinine. A 5-year follow-up included 15 parathyroidectomized (PTx) and nine conservatively followed cases, in a non-randomized setting, together with age-matched controls. Biochemical variables and body mass index (BMI) were investigated.

Results: At study entry, cases had higher calcium, PTH, glucose, low-density lipoprotein (LDL)/highdensity lipoprotein (HDL)-cholesterol, very low-density lipoprotein (VLDL)-cholesterol, total triglycerides, and BMI compared to controls $(P=<0.0001-0.035)$. The cases had a lower HDL-cholesterol value $(P=0.013)$ and one third of the cases had hypertriglyceridemia. During follow-up, the PTx cases decreased in calcium, PTH, LDL/HDL-cholesterol, total and LDL-cholesterol $(P=0.0076-0.022)$. Investigated biochemical variables remained adverse in conservatively followed cases during follow-up except a decreased LDL-cholesterol value. All surgically treated patients had parathyroid adenoma. Conclusions: Cases with normocalcemic pHPT have increased proatherogenic lipoprotein levels, BMI and glucose levels compared to age-matched controls. Parathyroidectomy has positive effects on some of these variables and reverses them to the same level as the controls, while conservative treatment fails to normalize the investigated metabolic variables.
\end{abstract}

European Journal of Endocrinology 155 33-39

\section{Introduction}

Primary hyperparathyroidism (pHPT) has been associated with an increased frequency of dyslipidemia, hypertension, overweight, impaired glucose tolerance, diabetes mellitus and increased incidence of morbidity and mortality of the cardiovascular system (1-9). Some studies have addressed the effects of surgery on these symptoms, but the results are diverging (5, 10-14). However, prior studies have been limited by a short follow-up time, performed in non-population-based cohorts and only investigated cases with apparent pHPT. Our own studies have focused on a cohort of post-menopausal women with mild pHPT, where positive effects on both dyslipidemia and bone mineral density have been found $(3,10)$. The effects of surgery have never been explored in normocalcemic patients with verified pHPT.
There have been questions about the existence of, and the very term 'normocalcemic pHPT' (15), and only a few previous studies have investigated this subject (16-19). The definition of 'normocalcemic pHPT' includes total albumin-corrected serum calcium within the normal range and serum parathyroid hormone (PTH) relatively elevated in comparison to the serum calcium level.

In this study, individuals with normal serum calcium and an inappropriately high serum PTH, recruited at a population-based health screening, were followed over 5 years. Thus, we aimed at identifying individuals with possible 'normocalcemic pHPT', and addressed three hypotheses. First, serum lipoprotein fractions as well as glucose metabolism differ in patients with "normocalcemic pHPT' compared to matched controls. Second, parathyroidectomy has positive effects on these metabolic variables. Third, conservative observation fails to have any positive effect on the evaluated metabolic parameters. 


\section{Subjects and methods}

At a population-based health screening of 5202 postmenopausal women, 30 cases with normal serum calcium and inappropriately high serum PTH were identified $(0.6 \%)$. We have previously reported findings on hypercalcemic patients with pHPT from this population $(3,10,20,21)$. We used previously described arbitrary limits as criteria for having possible 'normocalcemic pHPT' including an inappropriately high PTH value; serum calcium $2.50-2.60 \mathrm{mmol} / \mathrm{l}$ (upper normal range for normocalcemia $2.60 \mathrm{mmol} / \mathrm{l}$ ) and serum PTH $\geq 35 \mathrm{ng} / \mathrm{l}$ (normal range 12-55 ng/l), or serum calcium $<2.50 \mathrm{mmol} / \mathrm{l}$ and $\mathrm{PTH}>55 \mathrm{ng} / \mathrm{l}$ (20). Serum calcium and PTH were investigated at four consecutive occasions to rule out a temporary false value. One case had a slightly elevated serum creatinine level $(122 \mu \mathrm{mol} / \mathrm{l}$; normal range 64-106 $\mu \mathrm{mol} / \mathrm{l})$, while all others demonstrated normal values $(<98 \mu \mathrm{mol} / \mathrm{l})$. None of the cases had any family history of hypercalcemia, and all had normal or high urine calcium excretion to an extent excluding familial hypocalciuric hypercalcemia $(\mathrm{FHH})(20)$. The rationale for the diagnostic criteria is discussed elsewhere (10), but has also been surgically validated in 59 patients who had an adenoma removed with subsequent normalization of serum calcium and PTH values (20). Thus, we hypothesized that patients with both serum calcium and PTH within the normal range would suffer from pHPT, since a non-suppressed serum PTH ( $\geq 35 \mathrm{ng} / \mathrm{l})$ was present although, serum calcium was close to the upper reference range limit $(2.50-2.60 \mathrm{mmol} / \mathrm{l})$. The subsequently performed surgery supported this hypothesis, since 15 of the included normocalcemic cases also underwent parathyroid surgery. In each case, a solitary enlarged parathyroid gland was found during bilateral open exploration, and this was histologically verified as a parathyroid adenoma, mean weight $276 \mathrm{mg}( \pm 125$, range $120-491 \mathrm{mg})$. Twenty-four of the identified 30 individuals had a normal serum PTH value. An initial attempt to randomize the patients to either conservative treatment or parathyroid surgery in two groups failed due to presence of contra-indications for surgery or unwillingness to undergo surgery. Therefore, parathyroid surgery was performed on all included cases that accepted the surgery and had no general contraindications for it. This led to division of the patients into two groups; nine observed and 15 parathyroidectomized (PTx) patients (Fig. 1). There were no differences of biochemical variables between conservatively treated and later PTx cases at inclusion. A control individual was selected from the screened population by matching for age and quarter of year for biochemical analysis. Control individuals had serum calcium $<2.55 \mathrm{mmol} / \mathrm{l}$, serum creatinine $<146 \mu \mathrm{mol} / \mathrm{l}$ and a PTH level appropriate for the calcium level (20). Controls were excluded from further follow-up when the cases left the study.

Both cases and controls had similar smoking and daily exercise habits, and were well matched with respect to age. Difference in menopausal age averaged $5.0( \pm 4.05)$ years within the case-control pairs (20). No cases or controls had vitamin D or calcium supplementation during the follow-up period. At inclusion, one case and no controls were treated with lipid-lowering treatment. At the 5-year follow-up, two PTx cases, two conservatively followed cases and four controls had lipid-lowering treatment. Since lipoprotein fractions are one of the main investigated endpoints, the

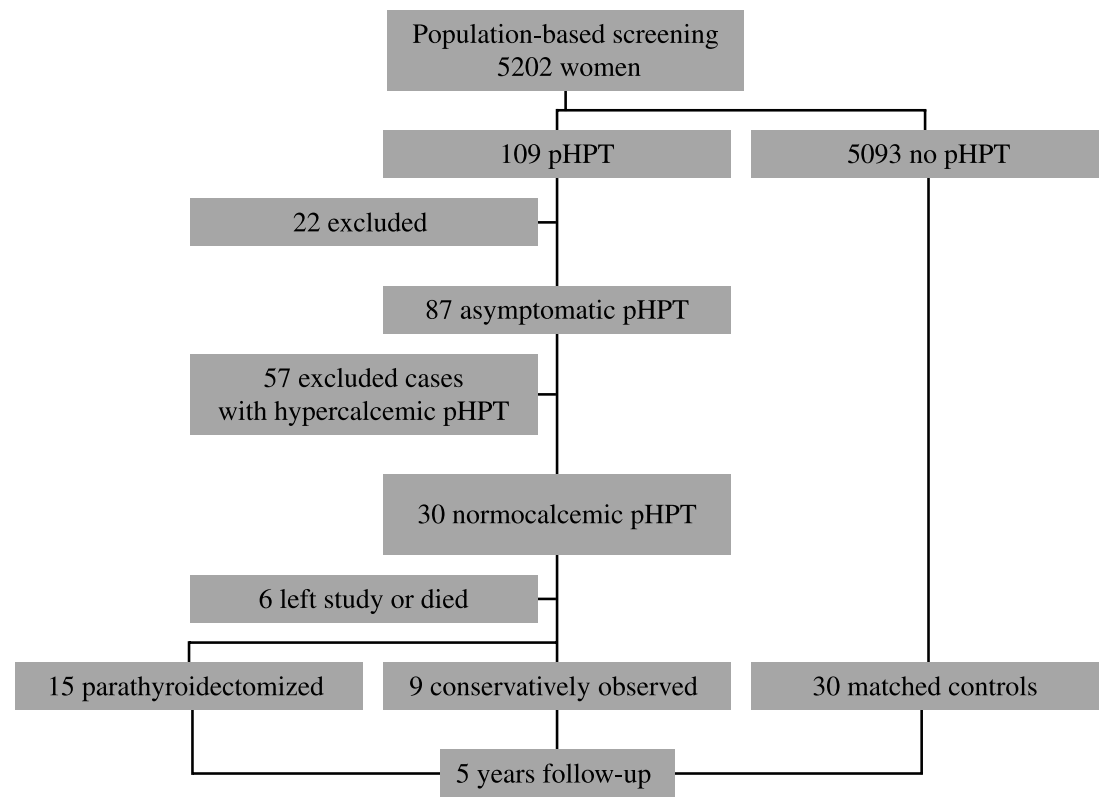

Figure 1 Flowchart of patients and controls in the follow-up study. 
data were stratified by lipid-lowering therapy. Only minor changes occurred after exclusion of these individuals. At different times during the follow-up period, three cases and four controls were treated with hormone replacement therapy (HRT; $2 \mathrm{mg}$ daily oral estradiol and $1 \mathrm{mg}$ noretistherone). Stratification of the data by HRT treatment did not change the results. All subjects gave informed consent to participate in the study, which was approved by the local Ethics Committee.

\section{Biochemistry}

Biochemical values were determined after an overnight fast. Total serum calcium (normal range 2.20-2.60 mmol/l) and spot urine calcium (normal range $0.6-5.0 \mathrm{mmol} / 24 \mathrm{~h}$ ) were measured using orthocresolphtalein dye binding. Serum calcium was corrected for serum albumin by using the normal mean for females more than 50 years old (22) and urine calcium was standardized by urine creatinine. Ionized plasma calcium (normal range 1.10-1.30 mmol/l) was determined with an ion sensitive electrode (Kone Instruments; Espoo, Finland), and serum creatinine (normal range 64-106 $\mu \mathrm{mol} / \mathrm{l})$ according to the Jaffe method. Intact serum PTH (normal range 12-55 ng/l) was measured with a radioimmunometric assay (Nichol's Institute; San Juan Capistrano, CA). Hemoglobin A1c (HbA1c) was evaluated by chromatography (normal range 3.8-5.2\%) and fasting serum glucose was measured with photometry (normal range 3.3-5.7 mmol/l). Body mass index (BMI) was calculated as the weight divided by the square of the body length $\left(\mathrm{kg} / \mathrm{m}^{2}\right)$.
Fasting total serum cholesterol, triglycerides and lipoprotein fractions were determined in a Technicon Auto Analyser II. Low density lipoprotein (LDL)cholesterol was calculated with Friedewald's formula: (total s-cholesterol)-(s-high density lipoprotein (HDL)cholesterol)-(total s-triglyceridesx0.45). The normal range for total serum cholesterol is $2.6-7.1 \mathrm{mmol} / \mathrm{l}$, for HDL-cholesterol $0.8-1.9 \mathrm{mmol} / \mathrm{l}$, and total triglycerides $0.23-1.70 \mathrm{mmol} / \mathrm{l}$. A total triglyceride value $>2.3 \mathrm{mmol} / \mathrm{l}$ and total cholesterol $>8.0 \mathrm{mmol} / \mathrm{l}$ were regarded as hypertriglyceridemia and marked hypercholesterolemia, respectively.

\section{Statistical analysis}

All analyses were defined a priori. Logarithmic transformation was performed to achieve normal distribution if necessary. All variables were normally distributed with the exceptions of LDL-cholesterol and urate. Wilcoxon's signed ranks test, Chi square test, multiple regression analysis and Spearman's rank correlation were used for statistical analyses. A P-value $<0.05$ was regarded as significant. Values are presented as mean and s.D., unless otherwise stated. JMP 5.1 (SAS Institute; NC, USA) was used for statistical analysis.

\section{Results}

\section{Inclusion}

Baseline characteristics and comparisons are shown in Table 1. As expected, at inclusion, the 30 identified normocalcemic individuals ('patients') with dysregulated

Table 1 Baseline characteristics of normocalcemic pHPT cases $(n=30)$ and controls $(n=30)$ at study inclusion.

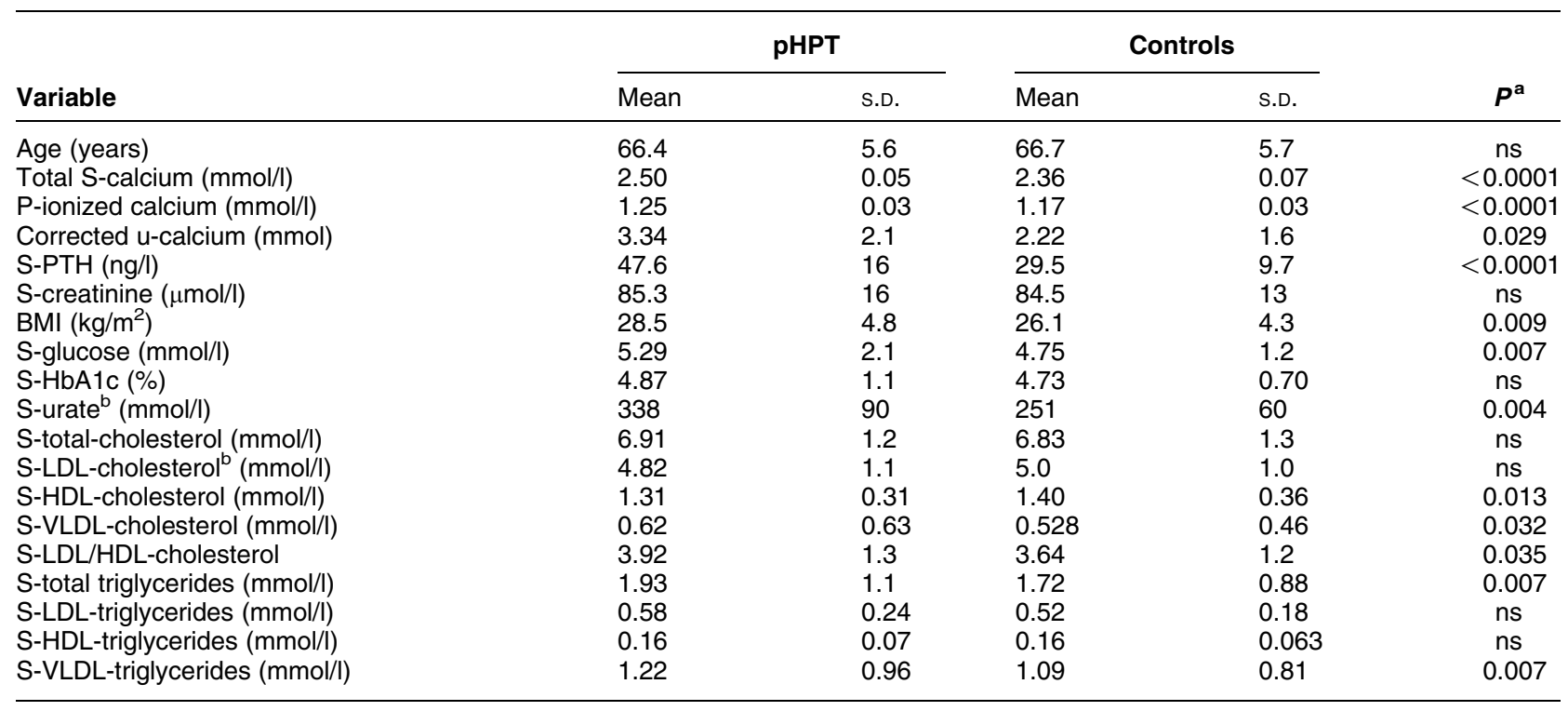

ns, not significant.

aNormocalcemic cases vs matched controls, Wilcoxon's signed ranks test.

${ }^{\mathrm{b}} \mathrm{S} k e w e d$ variable, presented as median \pm s.D. 
calcium/PTH values had higher serum calcium and PTH values than the matched controls $(n=30)$. The cases had higher glucose. BMI, very low density lipoprotein (VLDL)-cholesterol, LDL/HDL-cholesterol ratio, total and VLDL-triglycerides, urate and a lower HDL-cholesterol than the controls $(P=<0.0001-0.035)$.

In the cases, total serum and ionized calcium correlated negatively with BMI $(P=-0.43-0.50$, $P=0.0085-0.025)$. Serum PTH did not correlate to any of the investigated variables. In the control individuals, total serum calcium correlated negatively to LDL triglycerides $(P=-0.5, P=0.007)$. In multiple regression analysis, BMI did not appear as a confounding factor for the differences in lipoprotein variables or glucose levels between cases and controls.

Ten cases had a total triglyceride level higher than $2.3 \mathrm{mmol} / \mathrm{l}$ (marked hypertriglyceridemia) compared to one control $(P<0.001)$. Four cases had a marked hypercholesterolemia $(>8.1 \mathrm{mmol} / \mathrm{l})$ vs two controls (ns). After exclusion of the case with lipid-lowering therapy there were only minor changes in values and differences.

\section{Follow-up PTx cases}

The follow-up examination was performed approximately 5 years after inclusion, and included 15 PTx cases (15 controls). Three cases had moved from the area or left the study for other reasons and three cases had died. Parathyroidectomy was performed $45.5( \pm 11)$ months before the follow-up investigation.

At the 5-year investigation, the operated cases had no biochemical signs of pHPT (Table 2). Of the other variables, the previously noted differences between cases and controls were absent at this investigation, except for PTH, HDL-cholesterol and serum urate. Over time, the PTx cases improved their values of total and LDL-cholesterol and the LDL/HDL-cholesterol ratio. Serum urate and glucose increased over time. The increase in glucose was mainly due to one case with normal values at inclusion, but who during follow-up developed diabetic glucose values.

After exclusion of two cases treated with lipidlowering drugs, there were only minor changes in differences over time or between PTx cases and controls.

\section{Follow-up of conservatively observed cases}

The nine cases that received no surgical or medical treatment increased their levels of serum calcium and PTH over time, although not significantly. However, these variables were significantly higher in the conservatively treated compared with PTx cases $(P=<0.0001-0.028)$. The other investigated metabolic variables did not change over time, except LDL-cholesterol, which decreased $(P=0.043)$. When comparing conservatively observed cases with controls, total triglycerides, $\mathrm{HbAlc}$ and $\mathrm{BMI}$ were increased $(P=0.025-0.028)$, as were several others of the investigated variables, however, only numerically (not shown). After exclusion of the two cases treated with lipid-lowering therapy, no significant changes were seen over time. Compared with controls, the cases had increased PTH and BMI $(P=0.028-0.04)$. Calcium levels were higher, but the differences did not reach statistical significance.

Table 2 Variables at follow-up and cross-sectional parathyroidectomized cases $(n=15)$ and matched controls.

\begin{tabular}{|c|c|c|c|c|c|c|}
\hline \multirow[b]{2}{*}{ Variable } & \multicolumn{2}{|c|}{ PTx } & \multicolumn{2}{|c|}{ Controls } & \multirow[b]{2}{*}{$\begin{array}{c}\text { PTx vs controls } \\
P^{\mathrm{a}}\end{array}$} & \multirow[b]{2}{*}{$\begin{array}{c}\text { PTx over time } \\
P^{\mathrm{b}}\end{array}$} \\
\hline & $\begin{array}{l}\text { Baseline } \\
\text { Mean士s.D. }\end{array}$ & $\begin{array}{l}\text { Follow-up } \\
\text { Mean } \pm \text { s.D. }\end{array}$ & $\begin{array}{l}\text { Baseline } \\
\text { Mean士s.D. }\end{array}$ & $\begin{array}{l}\text { Follow-up } \\
\text { Mean士s.D. }\end{array}$ & & \\
\hline Total S-calcium (mmol/l) & $2.50 \pm 0.04$ & $2.3 \pm 0.1$ & $2.35 \pm 0.07$ & $2.37 \pm 0.07$ & ns & 0.007 \\
\hline P-ionized calcium (mmol/l) & $1.25 \pm 0.03$ & $1.12 \pm 0.06$ & $1.17 \pm 0.03$ & $1.16 \pm 0.03$ & ns & 0.007 \\
\hline S-PTH (ng/l) & $48.4 \pm 13$ & $41.5 \pm 14$ & $30.0 \pm 8.3$ & $29.6 \pm 7.4$ & 0.041 & ns \\
\hline BMI $\left(\mathrm{kg} / \mathrm{m}^{2}\right)$ & $27.9 \pm 3.6$ & $28.5 \pm 4.2$ & $25.0 \pm 3.5$ & $25.6 \pm 4.3$ & ns & ns \\
\hline S-glucose $(\mathrm{mmol} / \mathrm{l})$ & $4.78 \pm 0.45$ & $5.26 \pm 0.99$ & $4.61 \pm 0.83$ & $4.89 \pm 0.97$ & ns & 0.036 \\
\hline S-HbA1c (\%) & $4.66 \pm 0.43$ & $4.79 \pm 0.52$ & $4.53 \pm 0.53$ & $4.4 \pm 0.22$ & ns & ns \\
\hline S-creatinine $(\mu \mathrm{mol} / \mathrm{l})$ & $89.9 \pm 21$ & $92.9 \pm 25$ & $84.2 \pm 15$ & $81.8 \pm 10$ & ns & ns \\
\hline S-urate $(\mathrm{mmol} / \mathrm{l})$ & $323 \pm 106$ & $354 \pm 104$ & $252 \pm 61$ & $280 \pm 62$ & 0.0499 & 0.012 \\
\hline S-total-cholesterol (mmol/l) & $6.91 \pm 1.3$ & $6.25 \pm 1.2$ & $6.81 \pm 1.1$ & $6.34 \pm 1.2$ & ns & 0.022 \\
\hline S-LDL-cholesterol ${ }^{\mathrm{C}}(\mathrm{mmol} / \mathrm{l})$ & $4.63 \pm 1.2$ & $4.00 \pm 1.0$ & $4.98 \pm 1$ & $3.85 \pm 1.2$ & ns & 0.008 \\
\hline S-HDL-cholesterol (mmol/l) & $1.34 \pm 0.35$ & $1.33 \pm 0.35$ & $1.57 \pm 0.38$ & $1.74 \pm 0.47$ & 0.026 & ns \\
\hline S-LDL/HDL-cholesterol & $3.84 \pm 1.5$ & $3.12 \pm 1.1$ & $3.22 \pm 0.89$ & $2.45 \pm 1.0$ & ns & 0.022 \\
\hline Time after surgery (months) & - & $45.5 \pm 11$ & & - & - & - \\
\hline
\end{tabular}

PTx, parathyroidectomized; ns, not significant.

aParathyroidectomized cases vs matched controls, Wilcoxon's signed ranks test.

bParathyroidectomized cases comparing inclusion data with follow-up, Wilcoxon's signed ranks test.

${ }^{c}$ Skewed variable, presented as median \pm S.D. 


\section{Discussion}

In this study, metabolic variables in cases with normocalcemic pHPT are investigated. No previous report has specifically investigated cases with normal serum calcium and inappropriately high serum PTH, including PTH values within the reference range, close to the upper limit, identified from a large screened population. These patients' disturbances in metabolic variables or risk factors for cardiovascular morbidity and mortality have also never been described. The principal findings of this study are that cases with untreated normocalcemic pHPT have small but significant differences in serum levels of lipoprotein fractions and glucose, as well as BMI compared to matched controls. Normocalcemic cases with pHPT have a proatherosclerotic dyslipidemia, as well as increased fasting glucose and urate, at similar levels to hypercalcemic cases with pHPT recruited from the same screening program (3). The metabolic alterations, with increased levels of triglyceride-rich lipoproteins, glucose, urate and decreased HDL-cholesterol, together with increased BMI, are all included in the metabolic cluster of increased risk of cardiovascular diseases (23), potentially indicating a causal link between calcium and these alterations $(24,25)$. Increased BMI is in prior studies reported as an entity in pHPT $(9,26)$. The cases had an increased BMI compared to controls, which in multiple regression analysis did not explain the differences between cases and controls in lipoprotein variables or glucose levels. Parathyroidectomy has a positive effect on all metabolic variables except glucose, in the present study most likely due to the case that developed diabetes. The degree of the changes was small, but nevertheless potentially important. Recent studies have clarified that also small improvements in serum cholesterol, within the range described as normal serum values, have beneficial effects on cardiovascular disease risk (27). In cases followed conservatively, calcium and PTH continued to be high, and LDLcholesterol declined over time. The other investigated variables did not change, and the numerical levels remained at a level associated with increased cardiovascular risk.

The first pHPT treatment consensus conferences in 1990 did not discuss 'normocalcemic pHPT' (28). At the 2002 consensus conference, normocalcemic pHPT was appreciated as an entity of pHPT, however, defined as normocalcemia with elevated PTH (29). With the definition in the present study, cases with normocalcemic pHPT would be diagnosed in an even earlier phase than what was proposed at the most recent consensus conference. Some previous studies have included normocalcemic cases with normal PTH levels, however, without focusing specifically on these cases $(16,17,19)$. In both statements, the indications for surgery of pHPT are set well above the level of normocalcemia $(28,29)$.
Previous reports have documented that both mild and pronounced pHPT are associated with adverse effects on glucose and insulin metabolism, proatherosclerotic lipoprotein composition, overweight and hypertension (5-9, 11-13, 30-32). Cases with mild pHPT also have an increased risk of morbidity and mortality of the cardiovascular system (3, 33-35). Several populationbased studies and investigations with patients recruited consecutively have confirmed the association between pHPT and cardiovascular diseases, where both calcium and PTH are associated directly or indirectly with increased morbidity and mortality (2, 36-38). Moreover, in population-based studies, calcium per se, in the normal range without associated disturbances in serum PTH, also has a positive association with hard endpoints such as myocardial infarction $(39,40)$.

The present study was aimed at investigating prevalence of normocalcemic pHPT and exploring biochemical parameters in these individuals before and after treatment. Indeed, the distribution of a cohort of patients with pHPT would include a tail of normocalcemic individuals, which would overlap with the normal distribution of another cohort of individuals without pHPT. To securely identify patients with mild pHPT and normocalcemia within this interval of serum calcium included in the two cohorts may be difficult. However, among the normocalcemic patients in this series, the disease has been histopathologically proven as well as having improvements in their calcium and PTH levels after parathyroidectomy. We, therefore, feel it is safe to state that the selected individuals were recruited from a mild $\mathrm{pHPT}$ cohort rather than a cohort of normal individuals. Some investigators believe that normocalcemic and hypercalcemic HPT are two different entities, since cases with equal increases in PTH levels can have either hypercalcemia or normocalcemia, and remain stable in that relationship for several years (19). In other theories, the pHPT development is bi-phasic with an initial asymptomatic normocalcemic state that later evolves into hypercalcemia with symptoms $(41,42)$.

There is always a risk of introducing a type 1 error when performing multiple tests. However, all analyses were pre-specified according to our hypothesis. Overall, we used a limited number of statistical tests and the biological plausibility of our findings would argue against a type 1 error as an explanation for our findings. The results also extend the results found in previous studies with more severe pHPT.

The strengths of this investigation are that the study is based on individuals recruited in a large populationbased health screening and the long follow-up time. The cases were unaware of any metabolic disturbances at inclusion. In addition, the histopathologically proven parathyroid adenomas make the present investigation unique. The limitations of the study are the failure to randomize the cases into different treatments and the absence of vitamin D measurement, the latter partly due 
to the lack of sensitive assays available when patients were recruited. One case at inclusion, two cases in the PTx and two in the conservatively treated group were during follow-up treated with lipid-lowering therapy. There were only minor changes in results after exclusion of these cases.

Vitamin D deficiency may well be an important factor in the investigated group of individuals. Based on our knowledge of vitamin D deficiency we would anticipate parathyroid hyperplasia, while we found parathyroid adenomas, with weights of $120 \mathrm{mg}$ and above. Also urinary calcium was normal at study inclusion and in conservatively followed cases serum calcium increased numerically over time, arguing against vitamin D deficiency. Post-operative PTH values remained at a slightly high level, but not to the extent to indicate a possible vitamin D deficiency. This matter is still unresolved, but was not the main purpose of this study, and also difficult to enlighten due to missing vitamin D measurements at study inclusion.

The results of this study indicate that individuals with pHPT and serum calcium in the normal range may also exhibit metabolic variables associated with cardiovascular risks. Increased awareness of these parameters in normocalcemic pHPT patients is proposed, since also moderate improvements of proatherosclerotic lipoprotein fractions might be beneficial $(27,43)$.

\section{Acknowledgements}

Financial support: Swedish Medical Research Council, University of Uppsala, Selander's Foundation, Uppsala, Elgqvist's Foundation, Nybro.

\section{References}

1 Hedbäck G \& Odén A. Death risk factor analysis in primary hyperparathyroidism. European Journal of Clinical Investigation 199828 1011-1018.

2 Hedbäck G \& Odén A. Increased risk of death from primary hyperparathyroidism - an update. European Journal of Clinical Investigation $1998 \mathbf{2 8} 271-276$.

3 Hagström E, Lundgren B, Lithell H, Berglund L, Ljunghall S, Hellman P \& Rastad J. Normalized dyslipidaemia after parathyroidectomy in mild primary hyperparathyroidism: populationbased study over five years. Clinical Endocrinolology (Oxf) $2002 \mathbf{5 6}$ 253-260.

4 Valdemarsson S, Lindblom P \& Bergenfelz A. Metabolic abnormalities related to cardiovascular risk in primary hyperparathyroidism: effects of surgical treatment. Journal of Internal Medicine $1998244241-249$.

5 Ljunghall S, Lithell H, Vessby B \& Wide L. Glucose and lipoprotein metabolism in primary hyperparathyroidism. Effects of parathyroidectomy. Acta Endocrinologica (Copenhagen) 1978 89 580-589.

6 Procopio M, Magro G, Cesario F, Piovesan A, Pia A, Molineri N \& Borretta G. The oral glucose tolerance test reveals a high frequency of both impaired glucose tolerance and undiagnosed Type 2 diabetes mellitus in primary hyperparathyroidism. Diabetes Medicine $200219958-961$.
7 Ljunghall S, Palmér M, Åkerström G \& Wide L. Diabetes mellitus, glucose tolerance and insulin response to glucose in patients with primary hyperparathyroidism before and after parathyroidectomy. European Journal of Clinical Investigation 198313 373-377.

8 Taylor WH \& Khaleeli AA. Coincident diabetes mellitus and primary hyperparathyroidism. Diabetes/Metabolism Research and Reviews 200117 175-180.

9 Bolland MJ, Grey AB, Gamble GD \& Reid JR. Association between primary hyperparathyroidism and increased body weight: a metaanalysis. Journal of Clinical Endocrinology and Metabolism 200590 1525-1530.

10 Hagström E, Lundgren E, Mallmin H, Rastad J \& Hellman P. Positive effect of parathyroidectomy on bone mineral density in mild asymptomatic primary hyperparathyroidism. Journal of Internal Medicine 2006259 191-198.

11 Lacour B, Roullet JB, Liagre AM, Jorgetti V, Beyne P, Dubost C \& Drueke T. Serum lipoprotein disturbances in primary and secondary hyperparathyroidism and effects of parathyroidectomy. American Journal of Kidney Diseases 19868 422-429.

12 Christensson T \& Einarsson K. Serum lipids before and after parathyroidectomy in patients with primary hyperparathyroidism. Clinica Chimica Acta $1977 \mathbf{7 8} 411-415$.

13 Silverberg SJ, Shane E, Jacobs TP, Siris E \& Bilezikian JP. A 10-year prospective study of primary hyperparathyroidism with or without parathyroid surgery. New England Journal of Medicine 1999341 1249-1255.

14 Sitges-Serra A, Girvent M, Pereira JA, Jimeno J, Nogues X, Cano FJ \& Sancho JJ. Bone mineral density in menopausal women with primary hyperparathyroidism before and after parathyroidectomy. World Journal of Surgery 200428 1148-1152.

15 Monchik J. Normocalcemic hyperparathyroidism. In Textbook of Endocrine Surgery, p 424. Eds O Clark, Q Duh \& E Kebebew. San Francisco: WB Saunders, 2005.

16 Tordjman KM, Greenman Y, Osher E, Shenkerman G \& Stern N. Characterization of normocalcemic primary hyperparathyroidism. American Journal of Medicine 2004117 861-863.

17 Monchik JM \& Gorgun E. Normocalcemic hyperparathyroidism in patients with osteoporosis. Surgery 2004136 1242-1246.

18 Hagag P, Revet-Zak I, Hod N, Horne T, Rapoport MJ \& Weiss M. Diagnosis of normocalcemic hyperparathyroidism by oral calcium loading test. Journal of Endocrinological Investigation 200326 327-332.

19 Maruani G, Hertig A, Paillard M \& Houillier P. Normocalcemic primary hyperparathyroidism: evidence for a generalized targettissue resistance to parathyroid hormone. Journal of Clinical Endocrinology and Metabolism $2003 \mathbf{8 8} 4641-4648$.

20 Lundgren E, Rastad J, Thurfjell E, Åkerström G \& Ljunghall S. Population-based screening for primary hyperparathyroidism with serum calcium and parathyroid hormone values in menopausal women. Surgery $1997121287-294$.

21 Lundgren E, Ljunghall S, Åkerström G, Hetta J, Mallmin H\& Rastad J. Case-control study on symptoms and signs of "asymptomatic" primary hyperparathyroidism. Surgery 1998124 980-985.

22 Benson L, Ljunghall S, Groth T, Falk H, Hvarfner A, Rastad J, Wide L \& Akerstrom G. Optimal discrimination of mild hyperparathyroidism with total serum calcium, ionized calcium and parathyroid hormone measurements. Upsala Journal of Medical Sciences 198792 147-176.

23 Reaven GM. Banting lecture 1988. Role of insulin resistance in human disease. Diabetes 198837 1595-1607.

24 Resnick L. The cellular ionic basis of hypertension and allied clinical conditions. Progress in Cardiovascular Diseases 199942 1-22.

25 Levy J. Abnormal cell calcium homeostasis in type 2 diabetes mellitus: a new look on old disease. Endocrine 1999 10 1-6.

26 Grey A \& Reid I. Body weight and bone mineral density in hyperparathyroidism. Annals of Internal Medicine 1995123732.

27 Baigent C, Keech A, Kearney PM, Blackwell L, Buck G, Pollicino C, Kirby A, Sourjina T, Peto R, Collins R \& Simes R. Efficacy and safety of cholesterol-lowering treatment: prospective meta-analysis of data from 90,056 participants in 14 randomised trials of statins. Lancet $20053661267-1278$ 
$28 \mathrm{NIH}$. Consensus development conference statement. Journal of Bone and Mineral Research 19916 S9-S13.

29 Bilezikian JP, Potts JT Jr, Fuleihan Gel H, Kleerekoper M, Neer R, Peacock M, Rastad J, Silverberg SJ, Udelsman R \& Wells SA. Summary statement from a workshop on asymptomatic primary hyperparathyroidism: a perspective for the 21 st century. Journal of Clinical Endocrinology and Metabolism 200287 5353-5361.

30 Prager R, Schernthaner G, Niederle B \& Roka R. Evaluation of glucose tolerance, insulin secretion, and insulin action in patients with primary hyperparathyroidism before and after surgery. Calcified Tissue International 199046 1-4.

31 Taylor WH \& Khaleeli AA. Prevalence of primary hyperparathyroidism in patients with diabetes mellitus. Diabetes Medicine 1997 14 386-389.

32 Kumar S, Olukoga AO, Gordon C, Mawer EB, France M, Hosker JP, Davies M \& Boulton AJ. Impaired glucose tolerance and insulin insensitivity in primary hyperparathyroidism. Clinical Endocrinology (Oxford) $1994 \mathbf{4 0} 47-53$.

33 Almqvist EG, Bondeson AG, Bondeson L, Nissborg A, Smedgard P \& Svensson SE. Cardiac dysfunction in mild primary hyperparathyroidism assessed by radionuclide angiography and echocardiography before and after parathyroidectomy. Surgery 2002132 1126-1132; discussion 1132.

34 Lundgren E, Lind L, Palmer M, Jakobsson S, Ljunghall S \& Rastad J. Increased cardiovascular mortality and normalized serum calcium in patients with mild hypercalcemia followed up for 25 years. Surgery 2001130 978-985.

35 Smith JC, Page MD, John R, Wheeler MH, Cockcroft JR, Scanlon MF \& Davies JS. Augmentation of central arterial pressure in mild primary hyperparathyroidism. Journal of Clinical Endocrinology and Metabolism 200085 3515-3519.

36 Jorde R, Sundsfjord J, Fitzgerald P \& Bonaa KH. Serum calcium and cardiovascular risk factors and diseases: the Tromsö study. Hypertension 199934 484-490.
37 Jorde R, Bonaa KH \& Sundsfjord J. Population based study on serum ionised calcium, serum parathyroid hormone, and blood pressure. The Tromsö study. European Journal of Endocrinology $1999141350-357$.

38 Palmér M, Adami HO, Bergstrom R, Jakobsson S, Åkerström G \& Ljunghall S. Survival and renal function in untreated hypercalcaemia. Population-based cohort study with 14 years of follow-up. Lancet 19871 59-62.

39 Leifsson BG \& Ahrén B. Serum calcium and survival in a large health screening program. Journal of Clinical Endocrinology and Metabolism 199681 2149-2153.

40 Lind L, Skarfors E, Berglund L, Lithell H \& Ljunghall S. Serum calcium: a new, independent, prospective risk factor for myocardial infarction in middle-aged men followed for 18 years. Journal of Clinical Epidemiology $1997 \mathbf{5 0}$ 967-973.

41 Silverberg SJ \& Bilezikian JP. "Incipient" primary hyperparathyroidism: a "forme fruste" of an old disease. Journal of Clinical Endocrinology and Metabolism 200388 5348-5352.

42 Rao DS, Wilson RJ, Kleerekoper M \& Parfitt AM. Lack of biochemical progression or continuation of accelerated bone loss in mild asymptomatic primary hyperparathyroidism: evidence for biphasic disease course. Journal of Clinical Endocrinology and Metabolism 198867 1294-1298.

43 NCEP. Executive summary of the third report of the national cholesterol education program (NCEP) expert panel on detection, evaluation, and treatment of high blood cholesterol in adults (Adult Treatment Panel III). Journal of American Medical Association $20012852486-2497$.

Received 13 January 2006

Accepted 29 March 2006 